\title{
USO DE MODELAGEM MOLECULAR NO ESTUDO DOS CONCEITOS DE NUCLEOFILICIDADE E
} BASICIDADE

\section{Celeste Ferreira e Agnaldo Arroio*}

Departamento de Metodologia do Ensino e Educação Comparada, Faculdade de Educação, Universidade de São Paulo, Av. da Universidade, 308, 05508-040 São Paulo - SP, Brasil

\section{Daisy de Brito Rezende ${ }^{\#}$}

Departamento de Química Fundamental, Instituto de Química, Universidade de São Paulo, Av. Prof. Lineu Prestes, 748, 05508-000 São Paulo - SP, Brasil

Recebido em 17/12/10; aceito em 5/5/11; publicado na web em 29/6/11

\begin{abstract}
USING MOLECULAR MODELING TO STUDY NUCLEOPHILICITY AND BASICITY CONCEPTS. Molecular modeling enables the students to visualize the abstract relationships underlying theoretical concepts that explain experimental data on the molecular and atomic levels. With this aim we used the free software "Arguslab 4.0.1" (semi-empirical method) to study the reaction of 1-chloropropane with ethoxide in solution, known to lead to methyl propyl ether, through the $\mathrm{S}_{\mathrm{N}} 2$ mechanism, and propene, through the $\mathrm{E}_{2}$ mechanism. This tool allows users to calculate some properties (i.e. heat formation or electric charges) and to produce 3D images (molecular geometry, electrostatic potential surface, etc.) that render the comprehension of the factors underlying the reaction's progress, which are related to the structure of the reagents, and the process kinetic clearer and easier to understand by the students.
\end{abstract}

Keywords: visualization; molecular modeling; mental models.

\section{INTRODUÇÃO}

Os avanços na computação têm permitido a construção de softwares de alta performance, nomeadamente no que diz respeito ao uso de imagens 3D (tridimensionais) projetadas em duas dimensões que, devido a suas características, permitem uma melhor visualização dos modelos adotados pela comunidade científica para representar os arranjos atômicos e os processos envolvidos nos fenômenos químicos. Dada a natureza da Química, em que se buscam, incessantemente, representações de um mundo inacessível à percepção humana para a construção de diversos tipos de modelos (científicos, históricos, curriculares, escolares, mentais, etc.), ${ }^{1}$ o uso dessas ferramentas tem-se tornado muito útil na pesquisa e no ensino. De acordo com Gilbert, ${ }^{2}$ Russell e Kozma ${ }^{3}$ e Chittleborough e Treagust, ${ }^{4}$ um requisito essencial para o aprendizado da Química é a habilidade para formar modelos mentais. Sem um modelo mental apropriado, os estudantes não conseguem apreciar as relações entre a escala molecular e o fenômeno macroscópico observado, além de terem dificuldade em perceber a relevância e o papel da Química em suas vidas. De acordo com Gibin e Ferreira: ${ }^{5}$

"O uso de modelos é importante para o desenvolvimento da Ciência e, além disso, é parte integrante do processo de aquisição do conhecimento pelo ser humano" (p. 1809). ${ }^{5}$

A formação de modelos mentais, também designados visualizações internas, tem merecido, por parte de alguns autores, um forte apoio., ${ }^{2,-9}$ Embora seu uso seja generalizado, não há uma definição geral ou única do que possa ser entendido por modelo mental. Atualmente, vários pesquisadores se têm afastado da ideia inicial de que haveria algum

*e-mail: agnaldoarroio@yahoo.com

"Programa Interunidades de Pós-Graduação em Ensino de Ciências, USP isomorfismo entre as representações externas e os modelos que as pessoas têm ou constroem em suas cabeças, as representações internas. Neste trabalho, adotamos a perspectiva de modelo mental de Rapp, ${ }^{6}$ ou seja, a de se constituir em uma estrutura de conhecimento organizada e internalizada. As relações causais, temporais e espaciais dos conceitos encontrar-se-ão codificadas nessas estruturas, que podem ser usadas para simular o conceito, de forma a ascender pontos de vista alternativos e considerar possibilidades não aparentes ou difíceis de encontrar. Em consonância com Tversky, ${ }^{10}$ acreditamos igualmente que os modelos mentais não serão réplicas internas de informação externa, mas fragmentos, pedaços incompletos de informação que são recuperados em função das tarefas ou objetivos da pessoa. De acordo com as pesquisas de Ferk e Vrtacnik, ${ }^{11}$ os alunos preferem as representações 3D a outros tipos de representações e a correta percepção da estrutura molecular 3D é um passo básico, que deve preceder qualquer operação mental. Essa preferência deve-se ao fato de uma representação 3D ajudar os alunos a obterem uma melhor percepção do arranjo espacial dos átomos, da conectividade entre átomos e moléculas e das interações permanentes entre as várias entidades sub-microscópicas presentes em qualquer porção de matéria. Com esse tipo de software, os alunos podem construir modelos virtuais de pequenas moléculas orgânicas usando representações moleculares comuns (bola-vareta, traço, espaço preenchido e superfícies, por exemplo). Nesse ponto, salientamos que essa aliança entre Tecnologia e Ciência vem provocando, nas últimas décadas, várias transformações em setores muito relevantes da nossa vida cotidiana, como é o caso da Educação, ${ }^{12}$ ou mais especificamente, do ensino de Química.

O "Arguslab", à semelhança do "Hiperchem" (não gratuito), permite encontrar a geometria molecular de menor energia, calcular as energias dos orbitais, gerar visualmente superfícies de potencial eletrostático e imagens virtuais 3D do orbital molecular ocupado de maior energia (HOMO) e do orbital molecular não ocupado de menor energia (LUMO). Todos os modelos virtuais obtidos podem 
ser manipulados pelos alunos, sendo rotacionados e observados de diferentes ângulos, ou seja, este tipo de software permite um elevado grau de interatividade entre o aluno e as ferramentas a usar. Segundo a perspectiva construtivista, é quando os alunos estão fortemente engajados nas atividades da sala de aula que a elaboração de significados por parte destes é relevante. A possibilidade de também virem a entrar em contato com vários tipos de representação para a mesma molécula e, simultaneamente, visualizarem diferentes representações que destacam diferentes propriedades, leva a situações de ensino de particular interesse, uma vez que, ao veicular diferentes formas de representação do objeto molecular, estamos a dotar os alunos de um conjunto de formas de referência que os torna capazes de produzir generalizações adaptadas a cada situação, de modo a construírem seus próprios modelos mentais. Essas ferramentas também permitem construir modelos de interações entre moléculas, rodar moléculas e obter novos ângulos de interação, isolar estruturas, localizar centros reativos e, consequentemente, descrever o mecanismo de reações químicas.

Neste trabalho, pretendemos demonstrar que o uso desse tipo de ferramenta facilita a compreensão do mecanismo da reação de um haleto de alquila primário com uma base forte, o íon etóxido. Nessa reação, formam-se ${ }^{13}$ um éter, em cerca de $90 \%$ de rendimento ${ }^{14} \mathrm{e}$, minoritariamente, na proporção de $10 \%,{ }^{14}$ um alceno. Esse resultado experimental pode ser compreendido admitindo-se que, dos inúmeros choques possíveis entre as moléculas dos reagentes, serão mais favorecidos aqueles que conduzirem a produtos termodinamicamente mais estáveis, por rotas as menos energéticas possíveis. Esse raciocínio é perfeitamente explicado ao se admitir que esse resultado experimental possa ser devido à competição de dois mecanismos bem conhecidos e amplamente estudados, a substituição nucleofílica bimolecular $\mathrm{S}_{\mathrm{N}} 2$ e a eliminação bimolecular E2. Segundo essa proposta mecanística (Figuras 1 e 2), ambos os caminhos reacionais são concertados e realizam-se em um único processo elementar, em que a velocidade depende, portanto, de duas espécies, o substrato (haleto de alquila primário) e o nucleófilo/base (íon etóxido). No caso do mecanismo $\mathrm{S}_{\mathrm{N}} 2$ (Figura 1), o íon etóxido atua como nucleófilo e liga-se ao carbono polarizado positivamente da ligação $\mathrm{C}$-X, formando-se o éter pela liberação do grupo migrante $(\mathrm{X})$, sendo esse o mecanismo favorecido, como sugere o fato desse composto ser o produto preferencial da reação. ${ }^{14}$ No mecanismo E2 (Figura 2), o íon etóxido, atuando como base, retira o hidrogênio ligado ao carbono adjacente ao carbono substituído pelo grupo migrante $\mathrm{X}$, sendo que, ao mesmo tempo, o par de elétrons envolvido na ligação com o $\mathrm{H}$ ataca intramolecularmente o outro átomo de carbono, dando origem a uma ligação dupla com formação do produto minoritário, o alceno. ${ }^{14}$

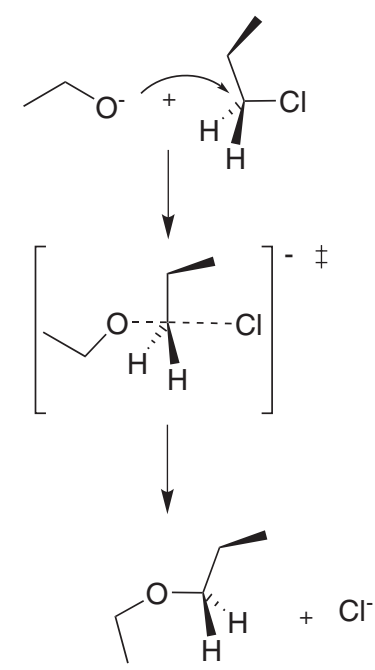

Figura 1. Ilustração do mecanismo de reação $S_{N} 2$

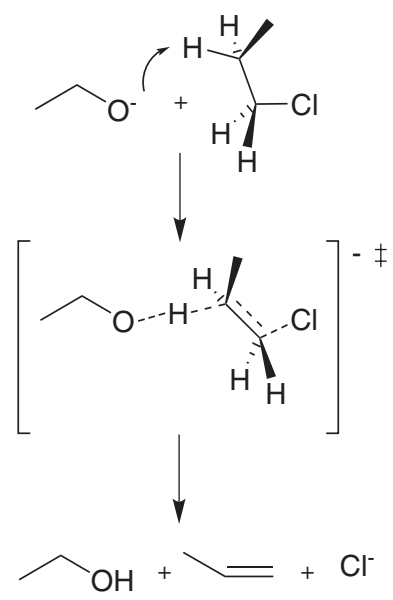

Figura 2. Ilustração do mecanismo de reação E2

Esse comportamento, isso é, a reatividade dessa classe de compostos orgânicos, pode ser compreendido considerando-se tanto a estrutura das substâncias presentes como a cinética da reação. Em síntese, pode-se generalizar que, em haletos de alquila primários e sem impedimentos estéricos no nucleófilo/base, predomina o mecanismo $\mathrm{S}_{\mathrm{N}} 2$. Nessas condições, o fato dos produtos do mecanismo $\mathrm{S}_{\mathrm{N}} 2$ serem cineticamente favorecidos é facilmente compreensível por haver, nesse caso, formação de uma ligação concertadamente à quebra de outra enquanto, na E2, verifica-se a quebra de duas ligações $\sigma$, concertadamente à formação de uma ligação $\pi$, aumentando a complexidade do processo, que seria mais lento.

Mas isso, por si só, não justifica a predominância do mecanismo $\mathrm{S}_{\mathrm{N}} 2$, porque com haletos secundários a competição desses dois mecanismos é mais equilibrada e, com haletos terciários, não há formação de produtos $\mathrm{S}_{\mathrm{N}} 2$. O mesmo resultado se obtém para nucleófilos/bases volumosas. A explicação para essas evidências experimentais se assenta na estrutura das substâncias e na estereoquímica da reação: os fatores que dificultam o acesso ao carbono polarizado da ligação C-X facilitam a formação de produtos pelo mecanismo E2.

Esse conjunto de explicações parecerá óbvio para um especialista em Química, como um pesquisador ou professor, mas, para um aluno do Ensino Médio, ou da graduação, será que também é óbvio? Qualquer aluno será capaz de construir mentalmente um modelo que lhe permita compreender bem esses fenômenos? A seguir, demonstraremos que, com o recurso dessas ferramentas, podemos produzir representações que facilitarão a compreensão dessas explicações por alunos treinados e auxiliados na visualização desse tipo de imagens.

\section{APLICAÇÃO DO SOFTWARE}

O software "Arguslab 4.0.1"15 é de acesso gratuito sendo, por isso, acessível a qualquer estudante de nível Médio ou Graduação e foi usado para o estudo da reação cuja equação está apresentada na Figura 3.

De acordo com os dados da literatura, ${ }^{16} \mathrm{e}$ como já foi referido, nessa reação competem dois mecanismos $\mathrm{S}_{\mathrm{N}} 2$ e E2, sendo o $\mathrm{S}_{\mathrm{N}} 2$ altamente favorecido. Segundo dados experimentais existentes igualmente na literatura, ${ }^{17}$ a cinética dessas duas reações é de segunda ordem, ou seja, na etapa lenta da reação estão envolvidos os dois reagentes, cujas moléculas precisam se chocar com a orientação e a energia adequadas para que a reação se desenvolva seja pelo mecanismo $\mathrm{S}_{\mathrm{N}} 2$, seja por $\mathrm{E} 2$. Vamos, então, começar por visualizar uma representação 3D (Figura 4A) de ambos reagentes obtida usando o método semi-empírico PM3, com as orientações necessárias para que a reação possa acontecer. O uso do cloreto de alquila, em vez do brometo de alquila, deve-se 


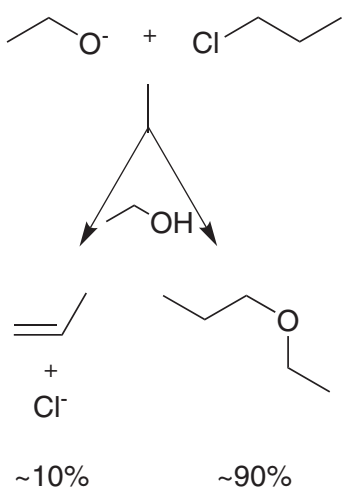

Figura 3. Equações para as reações competitivas de substituição e de eliminação que levam ao éter e ao alceno, respectivamente, a partir de 1-cloropropano
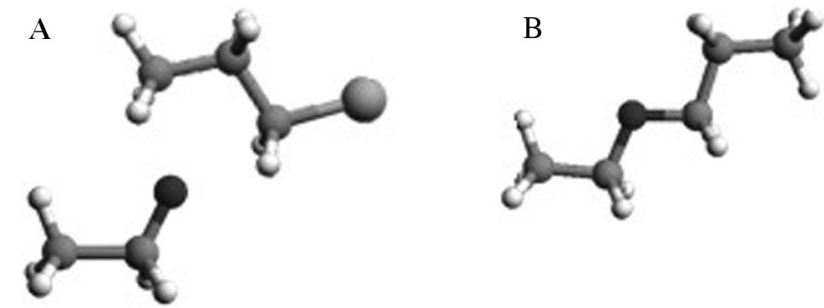

Figura 4. Orientação espacial das espécies envolvidas no processo $S_{N} 2$ estudado. A. Íon etóxido e confôrmero de menor energia do 1-cloro-propano(anti): aproximação do nucleófilo ao carbono $\alpha$ ao cloro é impedida estericamente. B. Produto obtido: éter etilpropílico

ao fato de não constarem dados para o elemento Bromo na base de dados do software empregado.

Nesse tipo de representação, torna-se mais fácil para o aluno construir seu próprio modelo mental acerca da geometria de cada uma das moléculas, porque temos uma distribuição espacial dos átomos, em cada molécula, consonante com o modelo atualmente aceito pela comunidade científica. $\mathrm{O}$ aluno não precisa possuir grandes habilidades visualizativas para compreender a representação, o que não acontece numa representação $2 \mathrm{D}$, em que a transposição posterior para uma representação 3D depende de suas capacidades de visualização. Para Gilbert, ${ }^{2}$ essas habilidades visualizativas compreendem: a) visualização espacial, i. e. habilidade para a compreensão de objetos tridimensionais a partir de objetos bidimensionais e vice-versa; b) orientação espacial, a habilidade de rodar um objeto, ou seja, mentalmente ser capaz de visualizar como vai ficar um objeto a partir de outra perspectiva e c) relação espacial, a habilidade de imaginar o efeito das operações de reflexão e inversão de um objeto.

Se o aluno não conseguir transpor corretamente a representação, ele construirá um modelo mental defasado do cientificamente aceito, que se constituirá em obstáculo à sua aprendizagem. No caso particular de uma reação química, a compreensão da estereoquímica da reação e, consequentemente, do mecanismo, depende fortemente da percepção do arranjo espacial dos átomos de cada molécula e de suas interações.

Vamos, agora, para simplificar, estudar, em primeiro lugar, o mecanismo $\mathrm{S}_{\mathrm{N}} 2$, em que, como já foi referido (Figura 1), o íon etóxido ataca nucleofilicamente o carbono da ligação $\mathrm{C}-\mathrm{Cl}$, doando um par de elétrons ao carbono e estabelecendo-se, dessa forma, uma ligação covalente $\mathrm{C}-\mathrm{O}$, concertadamente à saída do haleto.

Observando-se as imagens da Figura 4A, nota-se que, nessa conformação (anti, de menor energia - DI, Figura 5 - que é o resultado do cálculo executado pelo programa), há impedimento estérico ao ataque do nucleófilo. De fato, como se pode observar pelas imagens (Figura
4A), o nucleófilo se aproximaria do carbono polarizado positivamente pela parte de trás da ligação $\mathrm{C}-\mathrm{Cl}$, estabelecendo, progressivamente, uma ligação cada vez mais forte com o carbono, enquanto a ligação com o grupo migrante $(\mathrm{Cl})$ se tornaria cada vez mais fraca. Nessa situação, o nucleófilo experimenta impedimento espacial exercido pelo grupo metila vizinho ao carbono reativo. Nessa situação, as outras três ligações do carbono sofreriam uma flexão para o lado oposto, durante a reação, invertendo a configuração da estrutura e originando um éter, o éter etilpropílico (Figura 4B).

$\mathrm{Na}$ Figura 5, estão representadas conformações-limite para as moléculas de 1-cloro-propano; em condições ambiente, essas conformações existem em equilíbrio, em concentrações relativas inversamente proporcionais à magnitude da diferença de energia entre os confôrmeros. Analisando essas conformações das moléculas do composto (Figura 5, projeções de Newman e correspondentes em sela), nota-se que nas conformações de maior energia (eclipsadas, EIII) há menor impedimento estérico para o ataque do nucleófilo ao sítio reativo. Essas conformações estão em equilíbrio com aquelas de menor energia à temperatura ambiente, ou nas condições reacionais normalmente empregadas e são, portanto, as espécies reativas, sendo os equilíbrios deslocados para a reposição de EIII, à medida que essa espécie é consumida.

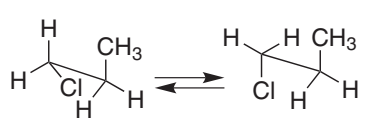

$$
\text { EI }
$$

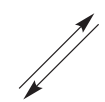

$\mathrm{Cl}_{\mathrm{H}}^{\mathrm{H}} \mathrm{CH}_{\mathrm{H}}^{\mathrm{H}_{3}} \rightleftarrows \mathrm{H}_{\mathrm{H}}^{\mathrm{Cl}}$

Ell
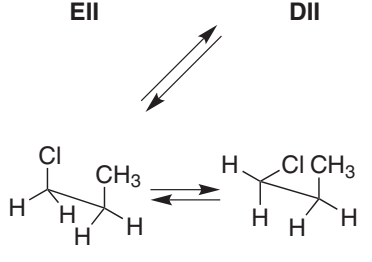

EIII

$$
\text { representação em sela }
$$

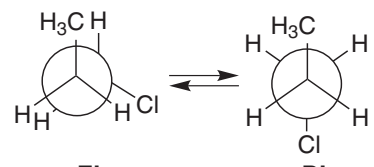

EI

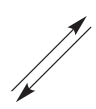

DI

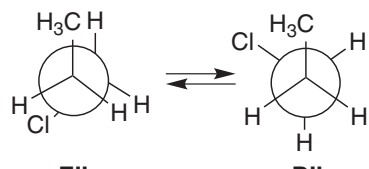

EII
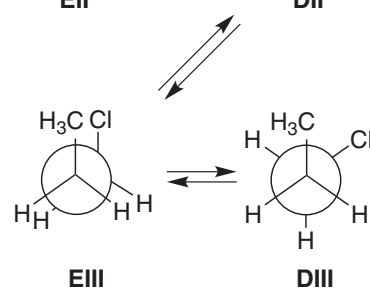

projeção de Newman
A: equilíbrios para confôrmeros de 1-cloropropano

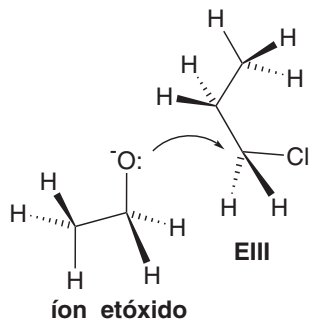

B: ataque ao confôrmero de menor impedimento estérico

Figura 5. A. Equilíbrios para os confôrmeros-limite do 1-cloropropano: representações em sela e respectivas projeções de Newman (as espécies representadas têm diferentes energias potenciais). B. Ataque ao confôrmero de maior energia 
A espécie EIII é mais favorável como reagente, não só porque não há impedimento estérico que dificulte o acesso da espécie nucleofílica ("janela de reação" do ataque), mas porque possui impedimento estérico intramolecular, que induz ao enfraquecimento da ligação $\mathrm{C}-\mathrm{Cl}$ (devido à aproximação dos orbitais moleculares HOMO e LUMO correspondentes à essa ligação, causada pela deformação na geometria da molécula; Figura 5). Esse resultado é importante para que os alunos percebam tanto as limitações das ferramentas computacionais, cujos resultados devem ser avaliados e validados pelo profissional que a elas recorre, como para problematizar concepções ingênuas de que as reações no estado fundamental envolvam sempre os confôrmeros de menor energia.

O recurso a esse tipo de software permite-nos, ainda, tornar mais perceptível porque o ataque do nucleófilo é mais efetivo neste ponto da molécula do haleto de alquila, supostamente a região mais positiva da molécula. Através de cálculos teóricos semi-empíricos usando o método AM1, o "Arguslab" constrói um mapa de potencial eletrostático (Figura 6) no qual podemos facilmente visualizar o melhor lugar para o ataque ocorrer, o que vem a confirmar os conceitos teóricos que estão subjacentes à formação de ligações entre átomos (forças de natureza eletrostática entre polos de carga de sinal contrário).
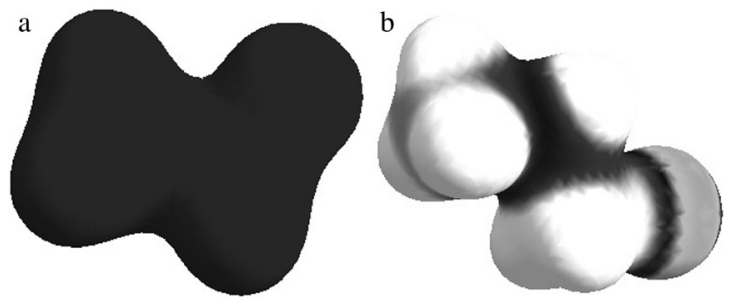

Figura 6. Mapas de potencial eletrostático construídos com o "Arguslab": a) íon etóxido; b) 1-cloropropano

Na Figura 6, as zonas mais claras representam regiões de potenciais mais positivos, ou seja, de deficiência de elétrons, enquanto as zonas mais escuras correspondem a potenciais mais negativos e, portanto, a maiores densidades eletrônicas. Não havendo qualquer impedimento estérico, o ponto mais eletrofílico da molécula do haleto de alquila é a região em que o ataque nucleofílico é mais efetivo, formando-se uma ligação mais forte entre o nucleófilo (íon etóxido) e o substrato (1-cloropropano) do que aquela existente entre o grupo migrante (cloro) e o carbono do substrato, formando-se um sistema mais estável.

Como referido anteriormente, o "Arguslab" é um software que permite aos alunos certo grau de controle sobre o curso da sua aprendizagem, ao possibilitar a manipulação pessoal da informação (geração de vários tipos de representação e cálculos associados) a que os alunos conseguem atribuir significado, relacionando as representações entre si. Esse tipo de software interativo possibilita, igualmente, aos alunos, iniciar seu contato com as práticas investigativas da Química.

O "Arguslab" permite, de acordo com o acima mencionado, compreender melhor esse mecanismo usando outra abordagem: a da teoria dos orbitais de fronteira estabelecida por Fukui. Quando os orbitais moleculares de dois reagentes começam a interagir e a se sobrepor, podemos dizer que a reação se iniciou, acabando na formação de dois novos orbitais moleculares um ligante, de menor energia e, outro, antiligante, de maior energia. No mecanismo $S_{N} 2$, a reação inicia-se pela interação do orbital ocupado de maior energia do íon etóxido (HOMO - Highest Occupied Molecular Orbital), que contém o par de elétrons que vai ser doado ao aceptor, o substrato orgânico com o orbital molecular não ocupado de menor energia (LUMO - Lowest Unoccupied Molecular Orbital), que é um orbital $\sigma^{*}$ envolvendo o grupo migrante. Assim, quanto mais alta for a energia dos orbitais
HOMO, menor a força de atração sobre o par eletrônico, que pode ser mais facilmente perdido ou doado; por outro lado, a facilidade de aceitação do par de elétrons pelos orbitais LUMO é aumentada pela diminuição da energia desses orbitais. Em outras palavras, quanto menor for a diferença de energia entre os orbitais HOMO e LUMO dos reagentes envolvidos, mais facilitada é a reação. A correspondente interação HOMO-LUMO entre um doador e um aceptor pode ser determinante e determinar o curso de uma reação. Através das representações seguintes podemos constatar que, nessa reação, o mecanismo é regido por esta interação forte entre o HOMO do nucleófilo (situado no átomo de oxigênio do grupo etóxido) e o LUMO do substrato orgânico, localizado no carbono ligado ao grupo migrante. Essa análise pode ser efetuada relacionando-se os valores obtidos para a energia dos orbitais e as correspondentes visualizações geradas pelo software.

Na Figura 7, obtida pelo método semi-empírico AM1, estão representadas as formas dos orbitais HOMO e LUMO do íon etóxido e do 1-cloropropano, respectivamente, onde a cor mais clara representa a parte negativa das funções de onda de cada orbital e, a cor mais escura, a parte positiva. Como se pode observar na Figura 7, quando os dois reagentes se aproximam segundo a orientação proposta (ataque nucleofílico pela parte de trás do átomo de carbono ligado ao cloro), verificamos uma forte sobreposição das funções de onda do orbital HOMO do átomo de oxigênio do íon etóxido que contém o par de elétrons doado para a ligação e o orbital LUMO do átomo de carbono que vai receber os elétrons. É também possível observar, na Figura 7, que se consegue uma forte sobreposição de duas funções de onda com o mesmo sinal, o que leva à formação de um orbital molecular ligante. Portanto, essa é a geometria de choque favorável à reação, sendo as demais colisões menos efetivas ou totalmente ineficientes.

Na Figura 7 é possível, também, observar, uma ligeira sobreposição das funções de onda com sinal contrário, que criará um nodo na região de coalescência. Este nodo representa uma região de ausência de densidade eletrônica, que contribui para o aumento das repulsões nucleares, criando um orbital molecular antiligante nessa região, diminuindo ligeiramente a ordem da ligação.

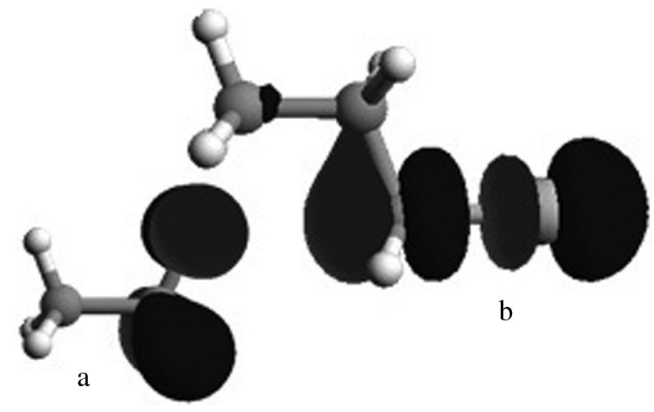

Figura 7. Orientação espacial dos orbitais na $S_{N} 2:$ a) orbital HOMO do íon etóxido; b) orbital LUMO do 1-cloropropano

De acordo com dados da literatura, como já foi referido anteriormente, também se forma um alceno (propeno) pelo mecanismo E2 embora, em solução, esse processo seja pouco competitivo para haletos de alquila primários. De uma forma simples, podemos dizer que a reação se dá pelo ataque da base a um hidrogênio concertadamente com a formação de uma ligação dupla C-C e quebra da ligação $\mathrm{C}-\mathrm{Cl}$, verificando-se, então, a formação de íon cloreto, do alceno e do álcool (Figura 2). A reação é estereoespecífica, a desprotonação deve ocorrer, geralmente, numa conformação anti em relação ao grupo abandonador e no mesmo plano. Sabendo que a reação é de segunda ordem, como já foi referido anteriormente, o mecanismo resulta de se 
colocar esses fatos juntos: no estado de transição teremos a formação e a quebra de duas ligações concertadamente.

Salientamos que o próton foi deslocado como numa típica reação ácido-base e o haleto migrante foi deslocado por um par de elétrons no fim da cadeia. $\mathrm{O}$ fato de a desprotonação ocorrer preferencialmente numa conformação anti é facilmente explicável; nessa conformação, os grupos estão alternados e existem menos repulsões, o que representa uma estrutura de menor energia, estabilizando o estado de transição. Finalmente, o ataque ao hidrogênio do carbono alfa é menos impedido estereoquimicamente e mais aberto ao ataque da base. No caso da reação em estudo, a otimização da geometria usando a mecânica quântica dá-nos uma conformação para o 1-cloropropano nada favorável para a ocorrência da reação via mecanismo E2. De acordo com o referido anteriormente, o ataque da base deve ser a um hidrogênio coplanar, preferencialmente em posição anti ao grupo migrante, hidrogênio esse que não encontramos na conformação obtida por otimização de geometria usando o método semi-empírico PM3 desse programa, conforme podemos constatar analisando a Figura 4. Entretanto, os confôrmeros de maior energia apresentam a relação adequada para essa eliminação que, ainda assim, é menos provável que a substituição devido aos fatores discutidos anteriormente e ao fato da geometria para a transferência de elétrons ao carbono, para a formação da ligação $\pi$ ser menos favorável do que para os eventos envolvidos na substituição.

Sendo assim, é facilmente aceitável que, nessa reação, não se formem produtos via mecanismo E2, ou então a quantidade formada deve ser bastante reduzida, uma vez que as condições estereoquímicas necessárias para a ocorrência dessa reação via mecanismo E2 são menos favoráveis.

\section{CONSIDERAÇÕES FINAIS}

Pensamos ter demonstrado, através deste exemplo, que o uso de imagens adequadas pode facilitar o processo de ensino-aprendizagem. A visualização de algo que está muito longe da nossa sensibilidade visual é um passo de gigante para a adequada construção de nossos próprios modelos mentais. Segundo Arroio e Honório, ${ }^{18}$ relações espaciais em visualizações moleculares podem ser muito difíceis de entender, mas com a ajuda de múltiplas representações, a compreensão de uma estrutura molecular pode tornar-se mais fácil pela comparação das diferenças entre elas. Também de acordo com vários autores, ${ }^{19}$ as atividades realizadas com o computador, segundo essa perspectiva, surgem como uma alternativa educacional que tende a atender às necessidades individuais dos estudantes, uma vez que a aprendizagem é, fundamentalmente, ativa, integrativa e reflexiva.

No caso concreto do assunto em estudo, nucleofilicidade versus basicidade, pensamos ter mostrado como se pode contribuir para sua compreensão, em detrimento da simples memorização, isto é, ao favorecimento da percepção pelos alunos do raciocínio lógico subjacente à proposição dos modelos explicativos para os fenômenos experimentais observados. No caso, à explicação de por quê, apesar de o íon etóxido ser considerado uma base forte de Lewis, atuar como nucleófilo, atacando o carbono eletrofílico, devido ao controle cinético da reação. Esperamos, assim, que ao usar esse tipo de ferramenta, o aluno não experimente somente um aumento de seu conhecimento conceitual de Química, mas que também experimente um incremento de suas capacidades de visualização, habilidades tão necessárias à aprendizagem em Química. Acreditamos, igualmente, que esse tipo de aprendizagem favoreça a transposição desse conhecimento para novas situações. Se, por exemplo, o substrato orgânico empregado tivesse algum impedimento estérico que impedisse o fácil acesso ao carbono eletrofílico, esperamos que o aluno fosse capaz de prever que o mecanismo $\mathrm{S}_{\mathrm{N}} 2$ não seria com certeza predominante e o rendimento da reação seria completamente diferente. Pensamos, também, ter elucidado, com este exemplo, que o comportamento de qualquer espécie numa reação depende não só das condições reacionais (temperatura e estado físico, por exemplo), mas também, da estrutura das espécies envolvidas.

\section{MATERIAL SUPLEMENTAR}

Está disponível gratuitamente em http://www.quimicanova.sbq. org.br, na forma de arquivo PDF, com acesso livre e consta de: Figura $1 \mathrm{~S}$. Orbitais HOMO do íon etóxido. Figura 2S. Orbitais LUMO do 1-cloropropano. Figura 3S. Orbitais HOMO do íon etóxido. Figura 4S. Orbitais LUMO do 1-cloropropano.

\section{REFERÊNCIAS}

1. Gilbert, J. K.: Boulter, C. J.: Elmer, R. Em Positioning models in science education and in design and technology education; Gilbert, J. K.; Boulter, C. J., eds.; Kluwer: Dordrecht, 2000.

2. Gilbert, J. K. Em Visualization: A Metacognitive Skill in Science and Science Education; Gilbert, J. K., ed.; Springer: Holland, 2007.

3. Kozma, R.: Russell, J.; Pupils Becoming Chemists: Developing Representational Competence; Gilbert, J. K., ed.; Springer: Holland, 2007.

4. Chittleborough, G.; Treagust, D. F.; Chemistry Education Research and Practice 2007, 8, 274

5. Gibin, G. B.; Ferreira, L. H.; Quim. Nova 2010, 33, 1809.

6. Rapp, D. N. Em Mental Models: Theorical issues for visualizations in science education; Gilbert, J. K., ed.; Springer: Holland, 2007.

7. Rapp, D.; Kurby, C. Em The 'Ins' and 'Outs' of Learning: Internal Representations and External Visualizations; Gilbert, J. K.; Reiner, M.; Nakhleh, M., eds.; Springer: Holland, 2008.

8. Briggs, M.; Bodner, G. Em A Model of Molecular Visualization; Gilbert, J. K., ed.; Springer: Holland, 2007.

9. Wu, H.; Shah, P.; Science Education, Inc. 2004, 88, 465.

10. Tversky, B. Em Cognitive maps, cognitive collages, and spatial mental models; Frank, U.; Compari, I., eds.; Springer-Verlag: Berlin, 1993.

11. Ferk, V.; Vrtacnik, M.; Blejec, A.; Girl, A; Int. J. Sci. Educ. 2003, 25, 1227.

12. Lacerda Júnior, V.; de Oliveira, K.; Silva, R.; Constantino, M. G.; da Silva, G.; Quim. Nova 2007, 30, 727.

13. Jones, M.; Ellison. B.; J. Am. Chem. Soc. 1989, 111, 1645.

14. Dhar, L.;Hughes, E. D.; Ingold, C. K.; Masterman, S.; Chem. Soc. 1948, $48,2055$.

15. http://www.arguslab.com, acessada em Dezembro 2010.

16. Carey, F.; Organic Chemistry, $7^{\text {th }}$ ed., McGraw-Hill: New York, 2007.

17. Smith, M.: March, J.; March's Advanced Organic Chemistry, $5^{\text {th }}$ ed., Wiley: New York, 2001.

18. Arroio, A.; Honório, K.; Problems of Education in the 21st Century 2008, 9, 17.

19. Arroio, A.; Honório K.; Weber, K.; Homem-de-Mello, P.; Silva, A.; Quim. Nova 2005, 28, 360. 
USO DE MODELAGEM MOLECULAR NO ESTUDO DOS CONCEITOS DE NUCLEOFILICIDADE E BASICIDADE

\section{Celeste Ferreira e Agnaldo Arroio*}

Departamento de Metodologia do Ensino e Educação Comparada, Faculdade de Educação, Universidade de São Paulo, Av. da Universidade, 308, 05508-040 São Paulo - SP, Brasil

Daisy de Brito Rezende ${ }^{\#}$

Departamento de Química Fundamental, Instituto de Química, Universidade de São Paulo, Av. Prof. Lineu Prestes, 748, 05508-000 São Paulo - SP, Brasil

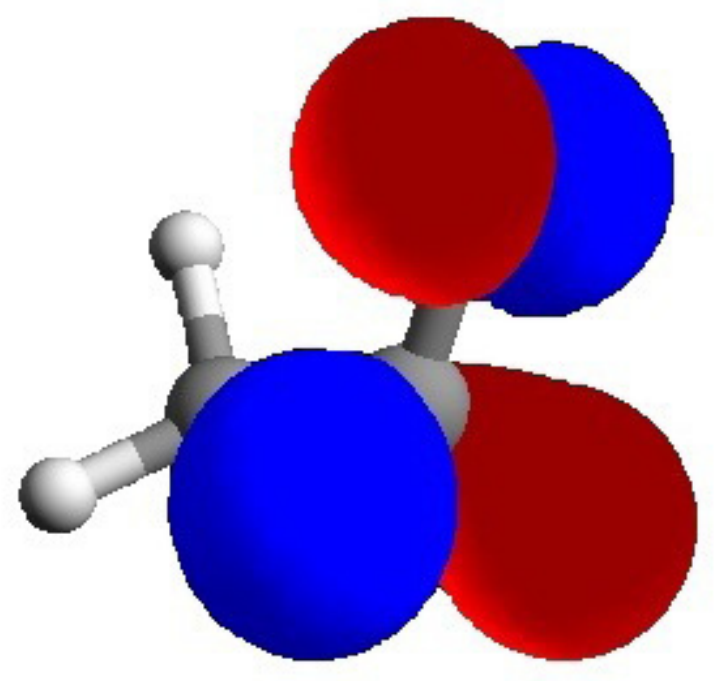

Figura 1S. Orbitais HOMO do íon etóxido

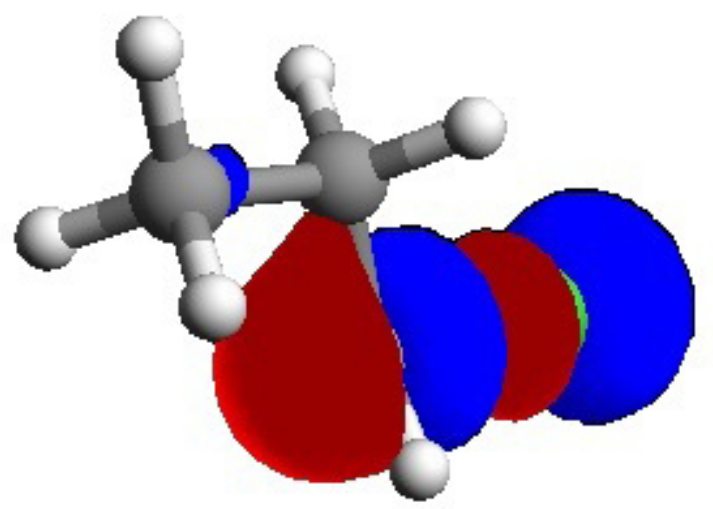

Figura 2S. Orbitais LUMO do 1-cloroprano

*e-mail: agnaldoarroio@yahoo.com

"Programa Interunidades de Pós-Graduação em Ensino de Ciências, USP

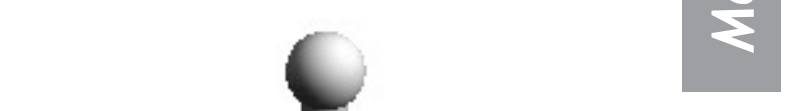

Figura 3S. Orbitais HOMO do íon etóxido

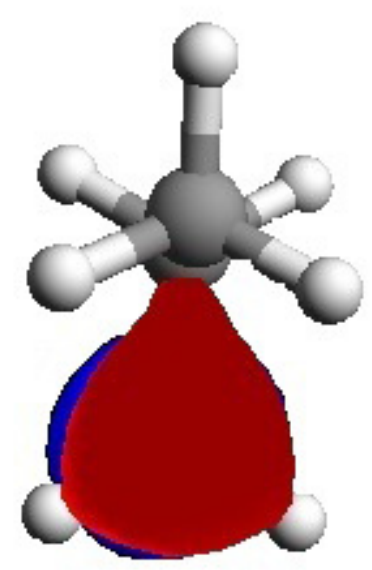

Figura 4S. Orbitais LUMO do 1-cloroprano 